\title{
ECOCAPSULE, SELF-SUSTAINABLE MICROHOME
}

\author{
Matej Pospisil \\ Mgr.art., Academy of Fine Arts and Design in Bratislava, Slovak Republic, \\ matej.pospisil@student.vsvu.sk
}

\begin{abstract}
Primary goal of the Ecocapsule is to colonise uninhabited and remote areas of our planet, our intention was to design a product which is eye-catching and different from container style housing, yet universal enough in terms of usability. We finally came up with the egg-shape - a very common and positive shape in all cultural backgrounds. The spheroid shape of Ecocapsule is designed to maximize the collection of rainwater and dew, and the design of the outer shell minimizes energy loss, too. But the egg-shape also brings challenges. For example, we cannot use prefab construction, furniture, or other equipment, so most of the interior is tailor made and customisable for clients. We wanted to design a home for 2 persons and their needs in different climate conditions. But we also wanted to keep Ecocapsule extremely mobile. With the current dimensions, Ecocapsule provides comfort of a hotel room for 2, yet it can be put on our custom-designed trailer by 2 person and towed by a car anywhere on road. It can fit into a standard shipping container and therefore can easily be shipped globally with the lowest shipping fees possible. Alternatively, it can be transported on a train, plane, or using helicopter. We also designed a special pontoon so Ecocapsule can work as a houseboat. Ecocapsule is powered by a dual system of energy production, which - in connection with highcapacity batteries - ensures energetic self-sufficiency even in the case of a temporary lack of sources. Ecocapsule also has an electric plug, enabling to charge the batteries from an external electric source if needed. The water filters ensure the transformation of water from any natural source into clean water. Hollow walls filled with highly efficient thermal insulation protect inhabitants from harsh environment and help achieve a performance almost on the level of a passive house. Off-grid functioning in different climate conditions from $-5^{\circ} \mathrm{C}$ to $+40^{\circ} \mathrm{C}$ is provided. The greatest challenge was to fit and combine all the systems HVAC, water, electricity, energy - within the limited space. Ecocapsule allows people to stay completely offgrid, yet with a comfort of a hotel room. This way it makes it very easy for its users to get in close touch with the nature and enables them to feel and act like insiders rather than observers from outside. This leads to greater connection and respect towards the natural environment. Ecocapsule is designed as a smart home via a smart home app users get real time overview of how much energy and water is being spent for e.g., taking a shower, cooking pasta or charging phone. This raises their consciousness of resources usage and helps them think about how they can downsize their consumption. At the same time, users can see how much resources is flowing in from the nature and how much is stored in batteries and water tanks. This encourages them to reflect upon limitedness and costs of resources. Ecocapsule is designed to offer just enough space for basic human needs. It inspires people to think about what they really need and so discourages them from surrounding themselves with items and creating unnecessary waste.
\end{abstract}

Keywords: Sustainability, Smart, Off grid 


\section{INTRODUCTION}

The architectural typology called the capsule has been used in contemporary architecture since 1960s, beginning mainly with most notable now-legendary projects of Archigram and of the Japanese Metabolists. The term "capsule" was first used for independent, mobile, and technologically equipped living an monofunctional units especially by English contemporaries Archigram and Cedric Price, and members of the Japanese group of Metabolists. Warren Chalk from Archigram began using the term capsule in 1964, for prefabricated mass-produced living units called Capsule Homes (Senk, 2018).

The original intention in creating the Ecocapsule project was to design housing for the artist on a plot of land without city networks, as an elaboration of an assignment to the Andes Sprout Society 2009 competition. Even though it did not win the award, its novel design resonated in design and architectural community, and after many positive reactions and inquiries from potential customers, we decided to bring it to life, originally from the studio Nice Architects. Longer-term stays away from engineering networks have always been marked by a lack of resources and the constant need to replenish supplies. This means high fuel consumption, time, accessory requirements and in particular, a negative impact on the environment. The project was initially developed as a residence for people who need to stay in challenging areas for a long period of time. Scientists, photographers, foresters, or extreme tourists. However, unit easy mobility, the possibility of transferring it by a container and especially its long-term energy independence has opened new ways of using this housing unit. Ecocapsule can be sent quickly and used as an accommodation for rapid response teams, e.g., in the case of damaged infrastructure or it can also be used as a small power plant and water filtration unit.

\section{DESIGN}

\subsection{Exterior}

The main part of the Ecocapsule is made of fiberglass components. The production takes place by manual lamination where in the process of assembly, metal structures are inserted, enabling the transmission of forces. The resin used in lamination is characterized by a low styrene content. The design of the composite elements was investigated by the finite element method to achieve the ideal ratio, the equilibrium state of its own weight and the load capacity of each part (Kolar, Nemec, and Kanicky, 2001). After inserting the closed steel structures and closing the shells, these spaces are filled with effective insulation to induce sufficient user comfort. The structures in the assembly process are then conductively and mechanically connected to guarantee static, dynamic and electrical safety. The exterior is dominated by a rich two-part glazing after the basic form, while the first, dark-colored shaped part has the task of protecting the interior from unwanted temperature gains during the day, Fig. 1. The external dimensions are similar to those from the automotive industry. Ecocapsule measures $4700 \mathrm{~mm}$ in length, $2200 \mathrm{~mm}$ in width and $2500 \mathrm{~mm}$ in height.

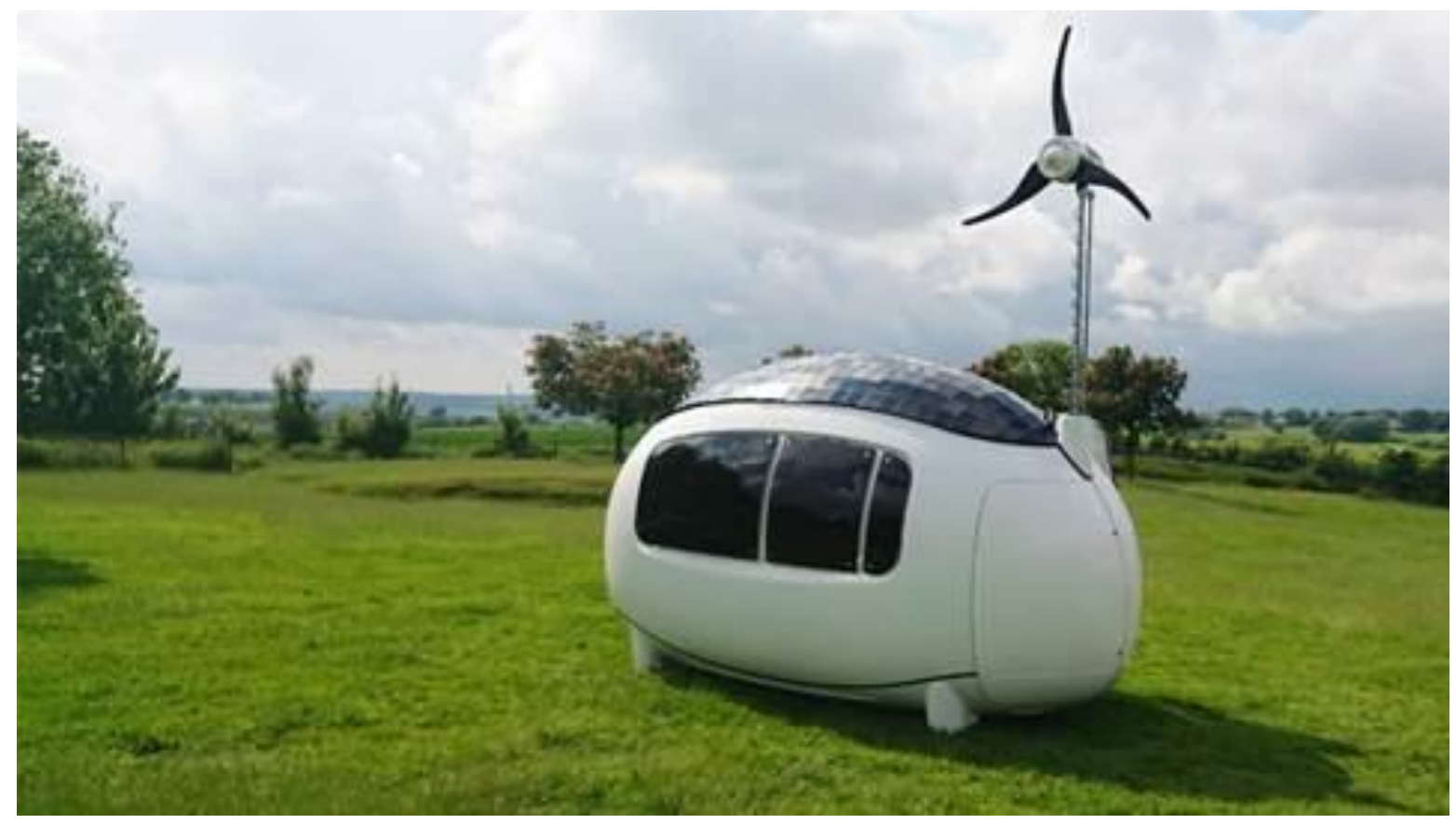

Fig.1. Ecocapsule 


\subsection{Interior}

The interior part is mainly made of lightened plywood with a low formaldehyde content, which is sensitively built into a double curved surface shown on Fig. 2. The interior layout guarantees comfortable living for two users, Fig. 3. There is a bathroom with a shower and a separate toilet. The living area is equipped with several storage compartments, in the back there is a kitchen with hob, sink and refrigerator, while the second, front part is primarily intended as a relaxation area with a folding bed and table. For optimal airflow protection, in addition to the use of a powerful air handling unit, it is possible to use opening windows and thus ventilate directly. The usable area is at the level of $6.3 \mathrm{~m} 2$ and the height of the ceiling is at the level of $2000 \mathrm{~mm}$ on average. Due to the manual production of composites, each manufactured piece of capsule differs in terms of geometric deviations, and it is necessary to adapt each manufactured piece of furniture to the surface.

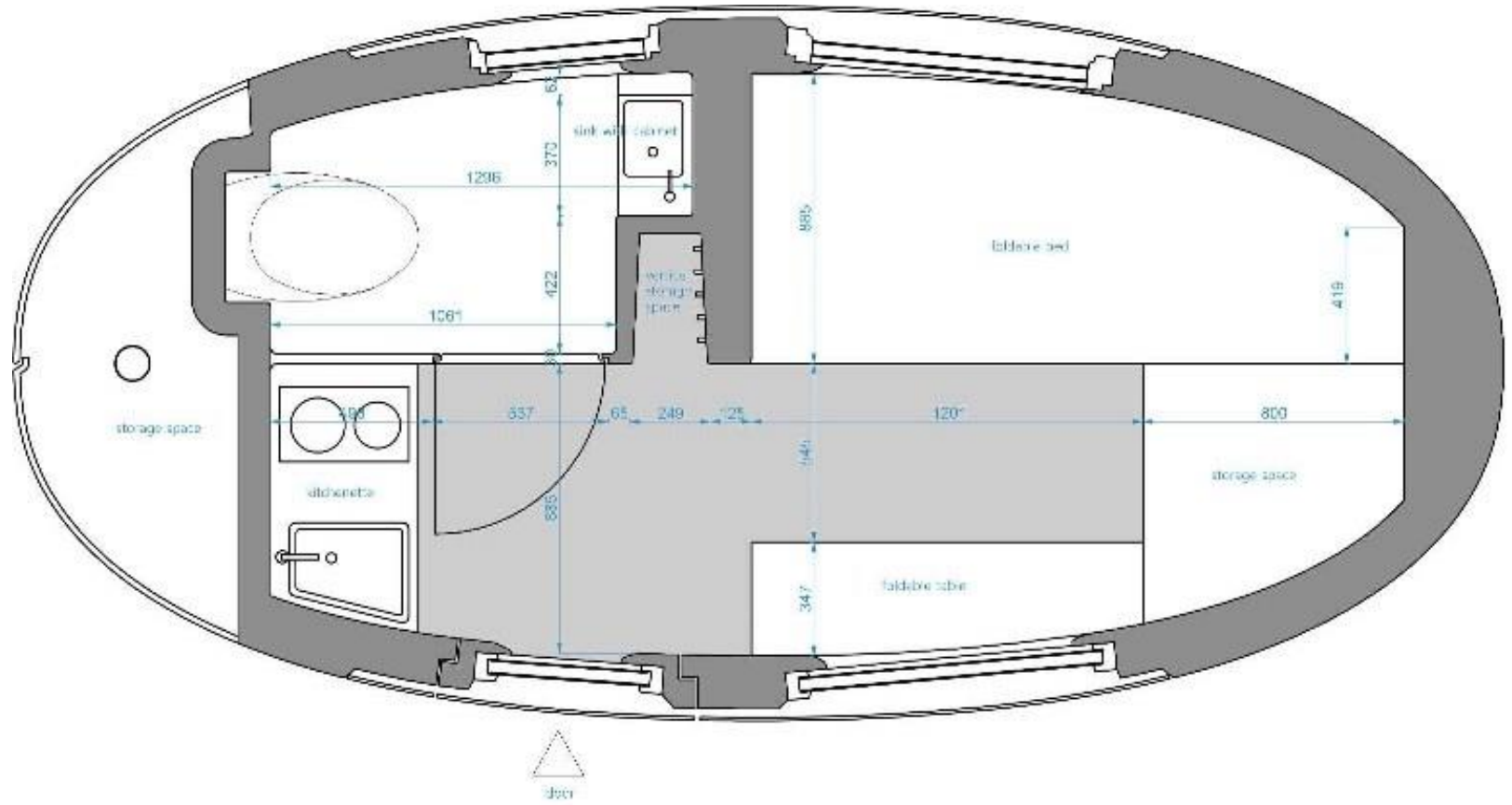

Fig. 2. Floorplan

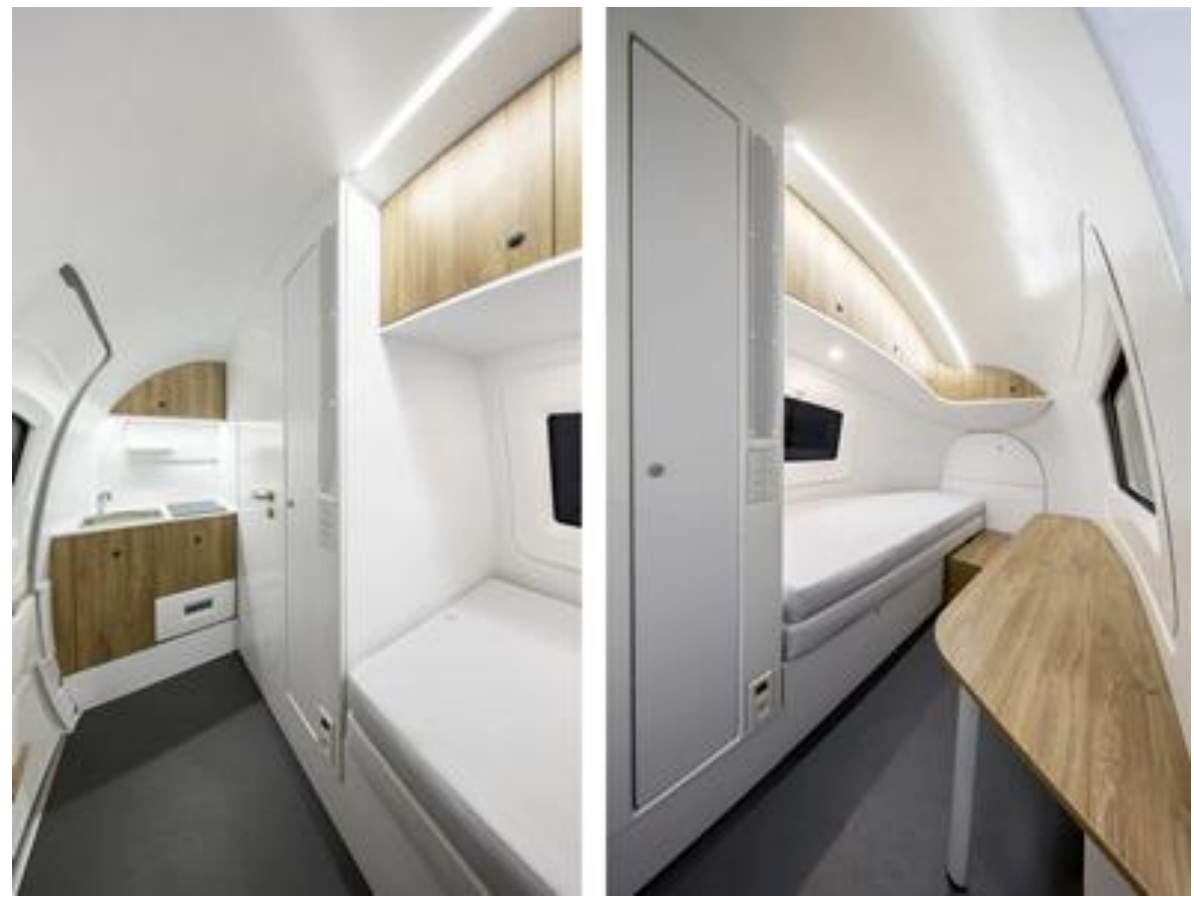

Fig. 3. Interior 


\section{SYSTEMS}

The overall self-sufficiency of the capsule is ensured by ingenious solutions in the field of installed systems. The system area is one of the complex and most costly solutions in the entire project. Smart solution includes an application based on PWA technology, which does not depend on the type of operating system and can be installed on any device. An undeniable advantage is the operation without internet access. The applications are used not only to inform the status of the device, but also to comfortably control it. The user is able to change the air conditioning settings, check the battery charge status, fluid levels in the tanks as well as check the correct settlement on the surface along with the prediction and control of current energy gains. The coordination scheme of all system elements is shown in the Fig. 4.

\subsection{Electrical system}

Ecocapsule is powered by a dual- energy production system that, in conjunction with high-capacity batteries $(9.7 \mathrm{kWh}-12.78 \mathrm{kWh})$, is capable of ensuring energy self-sufficiency even in the event of a temporary shortage of resources. Ecocapsule ${ }^{\circledR}$ also has the option of plugging into a conventional electrical outlet, so there is no problem recharging batteries from an external power source when needed. The roof consists of 4 panels with photovoltaic cells capable of producing $880 \mathrm{~W}$ of power that is used to recharge the batteries. A wind turbine that is mounted on a telescopic mast produces $750 \mathrm{~W}$ of power and is controlled from the technical space of Ecocapsule which can connect to a conventional electrical outlet through a Mennekes ${ }^{\circledR}$ outlet.

\subsection{Water system}

The water is obtained in two ways. The first one involves the collection of rainwater and the second one involves pumping water from any natural source (stream, lake, campsite water, etc.). The water is then cleaned using a chain of efficient mechanical filters. The filtration system is thus able to filter out up to $99.98 \%$ of bacteria thanks to built-in ultraviolet lamps. Wastewater from the objects in Ecocapsule is drained into 3 waste tanks. One tank is for the toilet waste and two tanks for grey water, where the waste from the sinks, kitchen, and shower is stored. The toilet waste is divided into a liquid and a solid part. Overall volume of water system tanks is 220 litres. Level sensors also helps to indicate the fullness of each tank.

\subsection{Ventilation system}

The air-conditioning and recuperation unit are used for the supply air into and out of Ecocapsule. The unit with recuperator is intended for ventilation and temperature adjustment. The supplied air must not be spoiled by chemicals, fuels, smoke, and other pollutants. The unit is wall-mounted and consists of a ventilation section and a compressor circuit. The ventilation part is mounted in a closed box containing fans, heat exchangers (condenser/evaporator) connected to the cooling circuit, actuators, recuperation exchanger, and filters. The compressor circuit is based on a compressor connected to the piping and cooling circuit elements by heat exchangers. HVAC unit efficiency of the air exchange level is $130 \mathrm{~m}^{3}$ per hour.

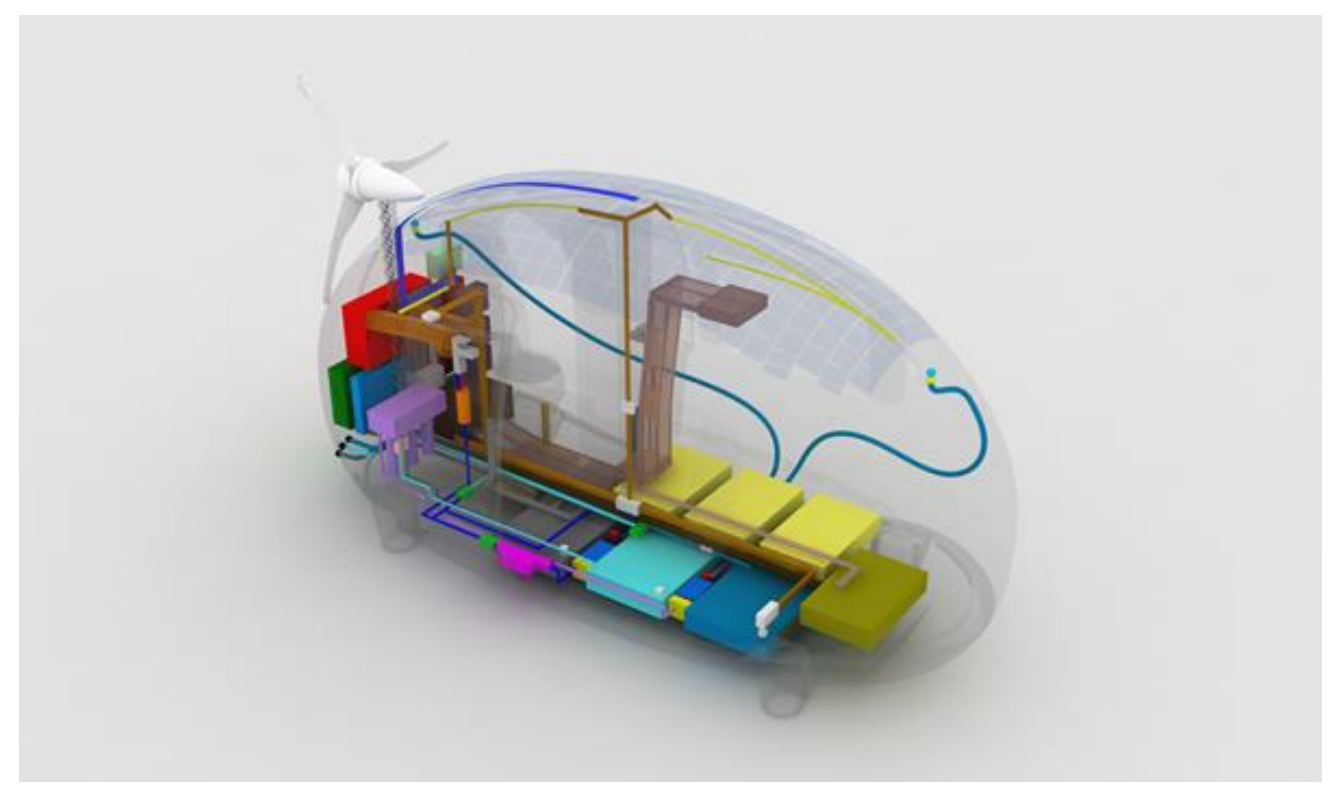

Fig. 4. Coordination scheme of systems 


\section{TRASPORTATION}

In the case of the Ecocapsule project, great emphasis was placed on easy transportability and efficiency. The overall dimensions are adapted to be placed in a standardized shipping container, which, in addition to global transport interoperability, also has an impact on the lower cost of transport than in the case of unique packaging. Other modes of transport shown on Fig. 5 include the possibility of loading with any transport lifting device and placing the capsule on the cargo space of the vehicle, while on the roof structure there are lifting eyes, capable of transport also by helicopter. A separate chapter is transport on a separate trailer, where there is the possibility of separate loading and folding of the capsule on site. If Ecocapsule has wheels, it would become just another type of caravan, and that is not exactly what Ecocapsule is. Currently it mostly offers ideal solution for people who have land without city networks and want to use for mid-term habitation, that mean for weekends, holidays etc. With a special designed trailer, it can be a cottage-like unit which you can move elsewhere whenever you feel like with standard SUV or off-road vehicle.

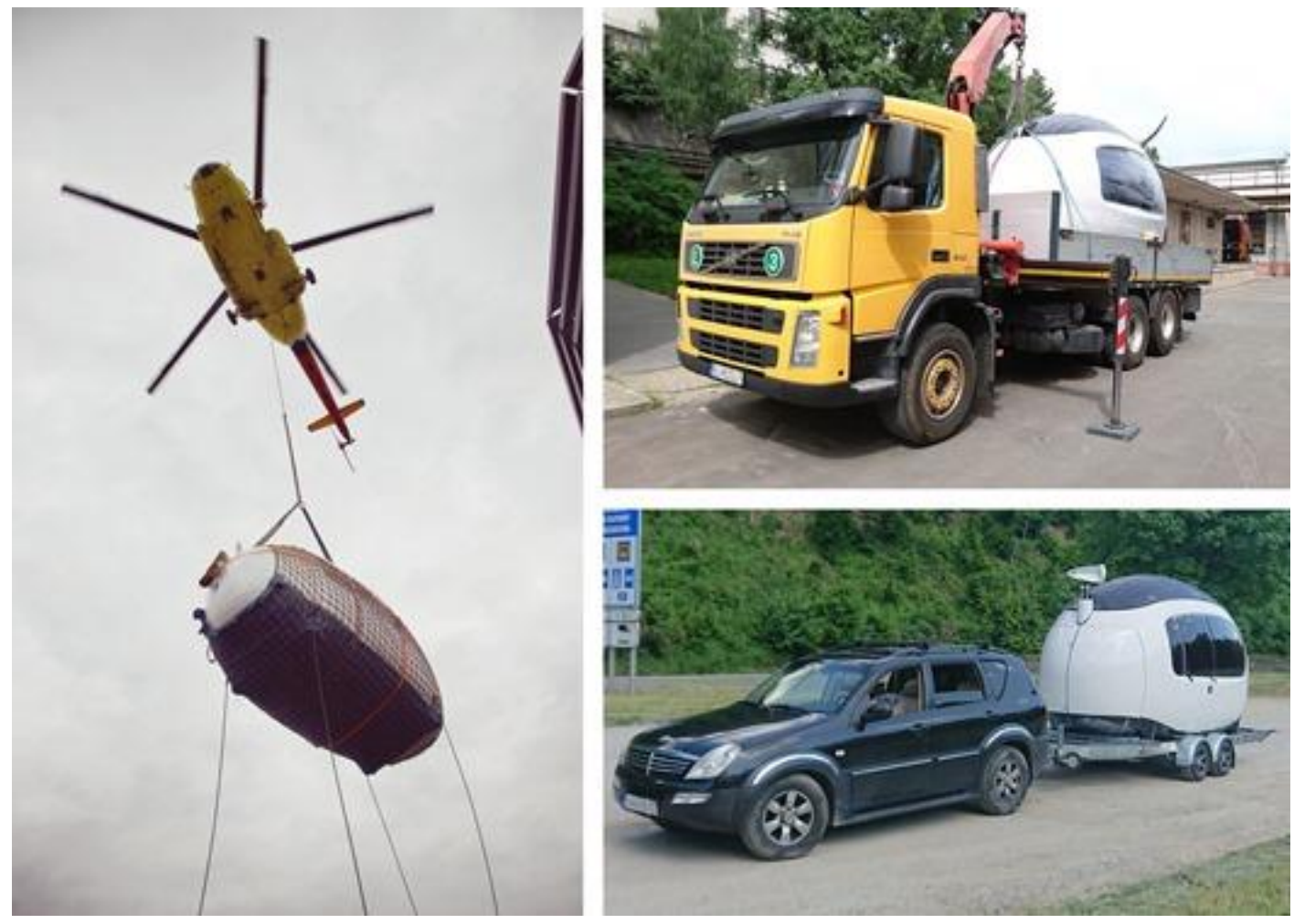

Fig. 5. Transport possibilities

For these purposes, a special covering was created to not only protect the surface while driving but also the aesthetically enhance the egg-shape during a stationary stand-by mode when the capsule is not in use, Fig. 6. The design of the cover respects the architectural approach to membrane structures in the case of synclastic forms shape. Synclastic form is where the main curvatures of the surface have a positive character (Shawkat, 2019). Preparing a cover use of geodesic curves in creating pattern with a focus on material savings. Patterning is process similar to fashion industry, which we can explain on a orange peel. If we peel the orange skin to many pieces, we will notice that each of these pieces will be flat lying on the surface (Sabmeethavorn, 2013). Softshell囚 with a weight of $295 \mathrm{~g} / \mathrm{m}^{2}$, which consists of PES fibres coated with thermoplastic polyurethane, appears to be a suitable material for covering the outer casing of the Ecocapsule, which is at the area of $24 \mathrm{~m}^{2}$, in ten pieces respecting the width of the bale of fabric, Fig. 7. 


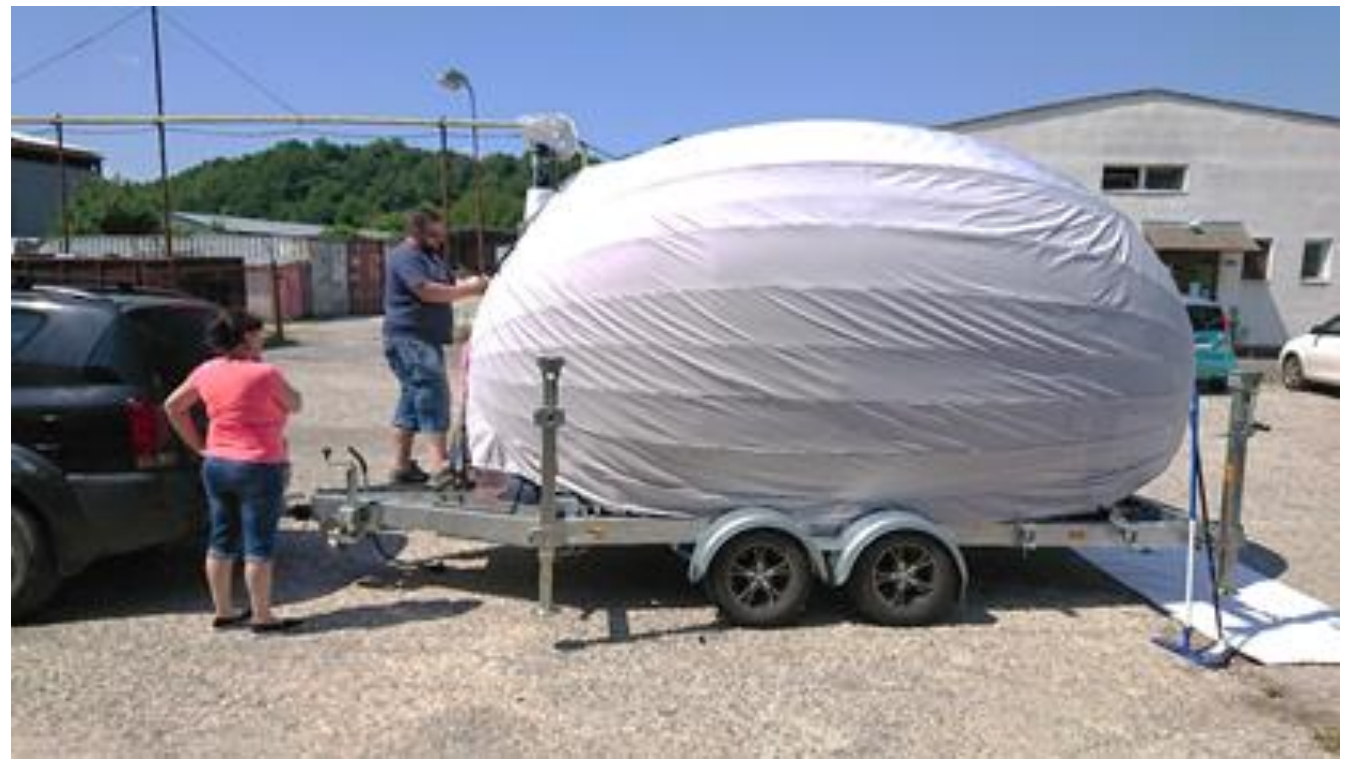

Fig. 6. Ecocapsule covering

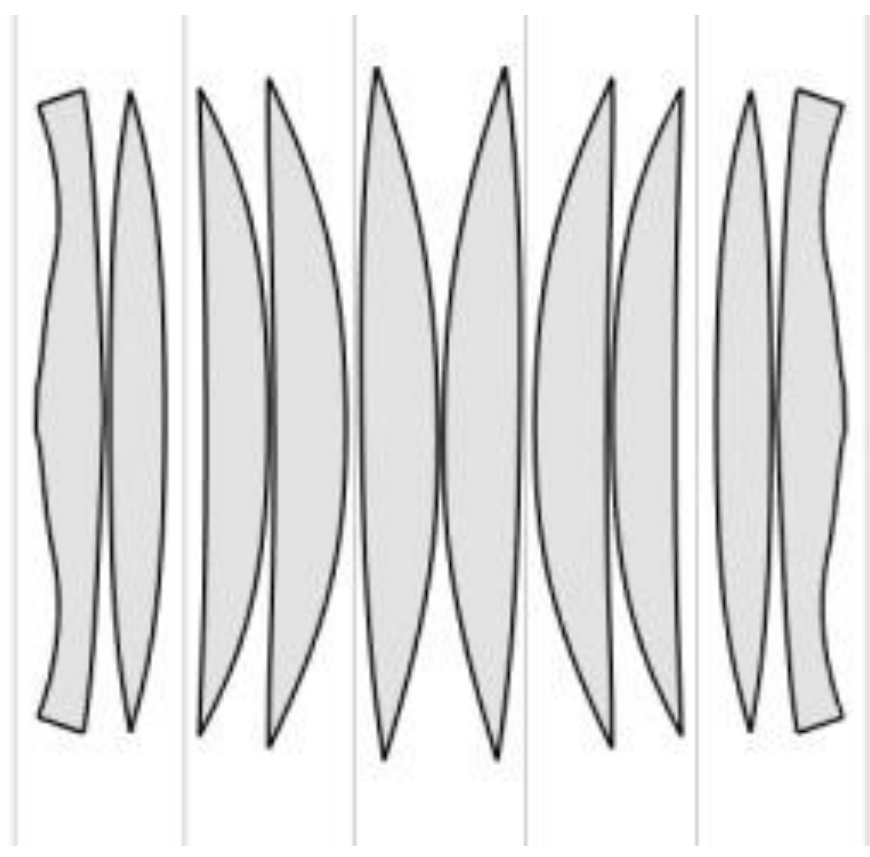

Fig. 7. Patterning

\section{CONCLUSION}

In the context of the post-corona world, we see new applications that are opening in front of us. Ecocapsule has a great potential not only in the travel business where it can be used as a virus-free accommodation but also in the medical segment where it can serve as a portable medical checkpoint, testing spot, or as an isolation unit. Of course, further optimization of the product is required. As a co-author and technical director of the project, I currently participate in the identification and application of possible structural optimization and innovative system solution. This includes greater use of recyclable materials, higher efficiency in terms of production technology and time, and the use of the largest possible ratio of local subcontractors possible. 


\section{REFERENCE LIST}

Kolar, V., Nemec, I., Kanicky, V. (2001). FEM principy a praxe metody konecnych prvku, Computer Press, Brno, $401 \mathrm{pp}$.

Sabmeethavorn A. (2013). Studio Detailing and Patterning, IMS Dessau, Germany

Senk, P. (2018). Capsules: typology of other architecture, Routledge, London, 207 pp.

Shawkat, S. (2019). Behavior of Steel Structures. Tribun EU, Brno, 312 pp. 